Fanum

Sociológico
Forum Sociológico

Série II

$26 \mid 2015$

Número 26

\title{
Transição para a vida adulta e práticas culturais na periferia metropolitana de Belo Horizonte: as trajetórias de Miro e Faro
}

Marco Marinho

\section{(c) OpenEdition \\ Journals}

Edição electrónica

URL: https://journals.openedition.org/sociologico/1195

DOI: 10.4000/sociologico.1195

ISSN: 2182-7427

Editora

CICS.NOVA - Centro Interdisciplinar de Ciências Sociais da Universidade Nova de Lisboa

Edição impressa

Data de publição: 12 dezembro 2015

Paginação: 43-52

ISSN: 0872-8380

Refêrencia eletrónica

Marco Marinho, «Transição para a vida adulta e práticas culturais na periferia metropolitana de Belo Horizonte: as trajetórias de Miro e Faro», Forum Sociológico [Online], 26 | 2015, posto online no dia 04 abril 2016, consultado o 29 março 2022. URL: http://journals.openedition.org/sociologico/1195 ; DOI: https://doi.org/10.4000/sociologico.1195 


\title{
TRANSIÇÃO PARA A VIDA ADULTA E PRÁTICAS CULTURAIS NA PERIFERIA METROPOLITANA DE BELO HORIZONTE: AS TRAJETÓRIAS DE MIRO E FARO'
}

\author{
Marco Marinho* \\ Pontifícia Universidade Católica de Minas Gerais, Faculdade de Ciências Humanas, Programa de Pós-Graduação \\ em Ciências Sociais (PPGCS-PUC Minas) \& Universidade Nova de Lisboa, Centro Interdisciplinar de Ciências Sociais \\ (CICS-NOVA)
}

\begin{abstract}
Resumo
O texto apresenta reflexões feitas em torno dos sentidos sociais das práticas culturais desenvolvidas por jovens residentes na periferia metropolitana de Belo Horizonte, especificamente no bairro Estrela D'alva, sítio famoso por concentrar episódios de violência, pobreza e projetos sociais. $O$ debate tem como referência os percursos sociais de Miro e de Faro e a condição juvenil como transição para a vida adulta analisada a partir do contexto social da periferia.
\end{abstract}

Palavras-chave: trajetória de vida; jovem da periferia; transição para a vida adulta

\begin{abstract}
This text presents reflections around the social meanings of cultural practices developed by young people living in the metropolitan outskirts of Belo Horizonte, specifically in the Estrela D'alva neighborhood, sites famous by focusing episodes of violence, poverty and social projects. The discussion makes reference to the social paths of Miro and Faro and the juvenile condition as a transition to adulthood analyzed from the social context of the periphery.
\end{abstract}

Keywords: life story; youngster from the periphery; transition to adulthood

\section{Introdução}

Este trabalho tem como pressuposto o conceito de juventude como etapa da vida em sociedade, como fase crucial da reprodução social, de transição para a vida adulta (Pais, 2009). Tal transição, segundo o autor, envolve um conjunto de experiências sociais que a demarcam e caracterizam-na como momento de construção da autonomia do indivíduo frente ao seu núcleo familiar e seus vínculos da infância. Esse momento de transição em nossa sociedade é identificado pelas experiências sociais caracterizadoras da entrada na vida adulta, os demarcadores de passagem, tais como "[...] inserção económica, independência económica, constituição de lar próprio, comportamentos em relação ao consumo, ao dinheiro e ao lazer, comportamentos familiares, estratégias matrimoniais e respetivos sistemas de valores." (Pais, 1991: 945). Tais experiências demarcam simbolicamente a conquista da autonomia relativa do indivíduo, como um momento de emancipação do sujeito, e funcionam como se fossem credenciais de integração ao mundo adulto que se sobrepõe à idade biológica dos sujeitos. Tornar-se adulto é deixar de ser criança, é assumir o papel de provedor de suas próprias necessidades e de seu próprio mundo quando possível, em um sentido máximo, agir como agente de seu destino.

Por de trás de toda a carga simbólica que envolve "tornar-se adulto" encontram-se as tensões relativas à transmissão dos capitais entre as gerações na sociedade, na qual os indivíduos buscam estabelecerem-se enquanto integrantes ativos e autônomos dos processos de produção e reprodução social. Tais processos envolvem o modo como a transição para a vida adulta é vivida pelos jovens em função de classe ou posição social (Pais, 1991). Ou seja, a inserção para a vida adulta e o destino dos jovens, embora incertos, são constituídos socialmente pelo legado de ações e experiências de vida das gerações anteriores como sugere o conceito de habitus presente em Bourdieu (2000). Segundo este 
autor (2000:163) o habitus representa "[...] uma maneira de ser, um estado habitual (em especial do corpo) e, em particular, uma predisposição, uma tendência, uma propensão, uma inclinação". Nesta perspectiva os percursos sociais dos indivíduos seriam conformados por tipos de comportamento duráveis e transponíveis entre gerações, estruturado a partir de um espaço social orientado, embora não seja determinado por este.

Se a juventude pode ser representada como um período de transmissão dos capitais, ela pode ser também notada como uma fase de descobertas do mundo e de si mesmo e, ao mesmo tempo, um período demarcado por incertezas em relação à consolidação de projetos de vida. Tendo no horizonte tais considerações, pode-se afirmar que a compreensão do social perpassa pela análise de como os jovens tecem seus percursos de vida, projetam suas ações perante os contextos sociais dos quais são parte. Neste sentido, propõe-se por meio da noção de trajetórias de vida construída através de etnografia e de relatos biográficos apresentar os percursos sociais de dois jovens residentes no contexto da periferia metropolitana de Belo Horizonte, o bairro Estrela $D^{\prime}$ alva². A partir de descrições tecidas de etnografia e de trechos das entrevistas biográficas realizadas com Miro e $\mathrm{Faro}^{3}$, subsidiadas pelas informações colhidas com moradores não-jovens, o texto prossegue com uma apresentação destes sujeitos e de seus itinerários em sociedade a partir do contexto social do bairro.

\section{Itinerários de vida de Miro e de Faro na periferia metropolitana}

Miro nasceu no norte de Minas Gerais, no Vale do Jequitinhonha e chegou ao Estrela D'alva aos 5 anos de idade, na época da entrevista estava com 22 anos, enquanto Faro estava com 21 e desde o nascimento vivia no bairro. Neste período Miro morava com a mãe e junto a três irmãos, Faro com o pai e uma irmã. Estes dois jovens, que conheci durante etnografia realizada em espaços de interação juvenil e práticas culturais, com destaque ao hip- $h o p^{4}$, se autodeclaram como "preto" e como "favelado", Miro afirmou ser "preto e favelado" e Faro disser ser um "negão aqui da favela". Ao dizerem isso demonstravam consciência da condição objetiva que desfrutavam na sociedade na qual o trabalho escravo e outras formas de trabalho degradante ainda operam como práticas sociais correntes embora a abolição oficial da escravatura esteja declarada há mais de um século. Ao retratarem o bairro como um todo sendo uma "favela", os jovens contestavam, sem saberem, o conceito de aglomerado subnormal amplamente utilizado pelas políticas públicas para classificação das áreas faveladas por este focar somente nas condições materiais de moradia e deixar de lado o contexto social que envolve a vida das pessoas na periferia da metrópole ${ }^{5}$.

As trajetórias de Miro e de Faro indicavam que o discurso bem articulado expresso pelas falas dos jovens durante as entrevistas trazia elementos doutras esferas de transmissão de capitais simbólicos pertinentes ao universo social da periferia que iam além dos capitais escolares, com destaque às experiências com o hip-hop e com a religião. Em relação a esta última, pode-se dizer que ocupou boa parte dos tempos vividos na infância e adolescência destes dois sujeitos. A participação na vida religiosa não se resumia somente ao cumprimento das atividades rituais como cultos, batizados e casamentos. Havia grupos de dança, teatro e outras atividades culturais promovidas pela igreja, a Primeira Igreja Batista do Estrela D'alva - PIBED, por meio das quais os jovens tinham oportunidades de conhecer coisas novas, como foi o caso da cultura hip-hop em início dos anos 2000. A participação religiosa exercida por Miro e por Faro abrangeu também, como para muitos outros do bairro, o compromisso com as Células - pequenos grupos de orações com encontros semanais nas residências dos seus membros - ambos os jovens foram líder de célula.

Durante a pesquisa de campo tive oportunidade de participar como observador destes encontros religiosos, as Células, por convite de Faro. Nestes eventos, além da pregação da "palavra de Deus", havia momentos reservados à escuta e ao debate dos problemas cotidianos de cada jovem que participava do grupo de oração. Nas Células os jovens interagiam através do convívio religioso que, na periferia, era marcado pelo trânsito intenso de pessoas, por abandonos e retornos. Por este motivo a igreja apresentava-se como um espaço de intenso trânsito social, havia uma alta rotatividade de fiéis, durante um culto as pessoas presentes nem sempre se conheciam, havia sempre novos participantes dispostos a "aceitar Jesus". Além disso, era comum encontrar as igrejas funcionando de portas abertas quase todos os dias da semana. A rotina das ruas na periferia era caracterizada, entre outras coisas, pela sonoridade estridente das igrejas que, ao competirem entre si, adotavam o barulho como estratégia para atrair a atenção das pessoas no espaço público. Somente uma rua do bairro tinha sete igrejas, quase todas pentecostais e uma evangélica tradicional da bandeira "Deus é Amor".

A presença maciça de igrejas e o intenso trânsito dos fiéis entre as instituições fazia com que o discurso religioso ecoasse por todos os lados da periferia. Na pesquisa de campo ouvia nas ruas, esquinas e bares as pessoas repetirem em situações corriqueiras do cotidiano os termos religiosos como "glória a Deus", "benção", "inferno", "Jesus", entre outros. A questão é que tal centralidade, atingida pelo discurso religioso, impacta as trajetórias dos 
indivíduos na periferia. Para Miro, por exemplo, o rompimento com a religião assumiu um significado de ruptura com uma moral que o jovem defendeu enquanto foi fiel na igreja, como um ponto inflexão em sua trajetória. Aos 17 anos de idade a desilusão religiosa representou para o jovem uma justificativa moral para legitimar sua adesão ao narcotráfico local. Para Faro o abandono da igreja foi menos radical e na época da pesquisa de campo o jovem mantinha um pé dentro e o outro fora da instituição, enquanto Miro não.

A etnografia mostrou que no bairro Estrela D'alva, além das igrejas e do comércio local, o tráfico de drogas encontrava-se presente em diversas esquinas e praças, as chamadas biqueiras, situadas no espaço público, faziam com que tais dinâmicas criminosas fossem marcantes na regulação da vida social. A ordem estabelecida pelo narcotráfico controlava os furtos e roubos no bairro por meio de punições exemplares, proibia as outras modalidades de crimes com a intenção de evitar a presença da polícia e ao mesmo tempo tranquilizar o ambiente das transações de compra, venda e consumo das substâncias ilícitas comercializadas. Neste ramo ilícito de atividade econômica a presença de mão de obra infantojuvenil era marcante, assim como nas igrejas o tráfico também era marcado por uma alta rotatividade. Na divisão do trabalho as crianças miúdas desempenhavam o papel de "olheiros" (agentes responsáveis em avisar a presença da polícia nas proximidades da biqueira) ou como "aviões" (transportando drogas, dinheiro ou armas) ou como "endolador" (pessoa que embala, antes da venda, as porções de droga em sacos plásticos), ou todas estas ocupações, além de atuarem também como mensageiros dos "toques de recolher" impostos aos moradores pelos narcotraficantes locais. No caso de Miro, o jovem atuou como "guerreiro" ou "soldado", era responsável por administrar e proteger a biqueira, ou seja, uma função na qual a disposição para a violência é um requisito necessário, ao passo que envolvia confrontos com polícias e/ou com grupos de narcotraficantes concorrentes. No tráfico Faro teve uma participação diferente, vendia pequenas quantidades de maconha para alunos de um colégio católico entre os 14 e 15 anos de idade quando trabalhou para a Cruz Vermelha.

Outras práticas sociais caracterizavam a vida social e a transição para a vida adulta na periferia, como a inserção precoce no mundo do trabalho. Faro, por exemplo, aos 13 anos de idade iniciou o exercício de atividades remuneradas através de ocupações informais, como a coleta de materiais recicláveis, ajudante na construção civil, auxiliar de limpeza, faxina doméstica, pintura de paredes, grafite, entre outras. Em sua trajetória a entrada precoce no mercado de trabalho teve reflexos sobre seus percursos noutras esferas sociais, como a escola. Aos
14 anos de idade, Faro encerrou seu vínculo com o sistema de ensino formal, uma decisão sua, sem interferência familiar. Seguindo essa mesma direção foram os percursos laborais de Miro, como catador de materiais recicláveis, embalador em supermercado, entre outros tão informais quanto estes, embora sua carreira escolar tenha seguido caminhos diferentes. Aos 20 anos de idade Miro concluiu o ensino básico por meio de supletivo (um atalho para os jovens com defasagem escolar, em até 6 meses por meio de exame de suplência consegue-se concluir o referente a 9 anos de escolarização). Aos 21 anos Miro chegou a ingressar à universidade, contudo neste último espaço permaneceu por pouco tempo, não concluiu o primeiro semestre do curso na Escola Federal de Belas Artes. A ausência de linearidade nos percursos escolares e o início precoce no trabaIho expressaram-se como tendências herdadas das relações familiares e comunitárias, e, por isso, não causaram aos jovens problemas de relacionamento familiar por se tratar de comportamentos relativamente esperados de jovens da periferia.

$\mathrm{Na}$ época da entrevista, além do hip-hop, Faro exercia a função de "articulador comunitário" no Centro de Referência da Assistência Social Casa Amarela - Cras Casa Amarela. Neste trabalho o jovem era responsável por acompanhar os assistentes sociais durante as visitas domiciliares, pelo atendimento ao público, e participava das reuniões de planejamento de estratégias de aproximação entre a equipe técnica do Cras e a comunidade local. Neste mesmo período Miro encontrava-se desvinculado do narcotráfico há pelo menos um ano e sua saída do "crime" foi marcada por uma forte adesão ao movimento de hip-hop no bairro. Este jovem, junto a outros, promovia duelos de rimas, apresentação de dança e mostra de filmes (cineclube) em espaços públicos do bairro, sempre com um discurso focado em questões sociais relacionadas aos problemas cotidianos da vida na periferia, ou seja, as ações eram voltadas para dar respostas a questões comunitárias, locais, o hip-hop era utilizado como instrumento de intervenção política e social na periferia.

Ao ter em conta a centralidade que a vida social da periferia demonstrou ter sobre os percursos juvenis, a seção seguinte apresenta uma breve contextualização urbana e social do bairro Estrela D'Alva realizada a partir do trabalho etnográfico.

\section{Contextualização urbana e social do bairro Estrela D'Alva realizada a partir do trabalho etnográfico com especial relevo para a presença de instituições religiosas como instituições sociais e políticas}

O objetivo desta seção é o de situar as experiências de vida de Miro de Faro a partir do contexto 
social do bairro Estrela D'alva6, na medida em que as trajetórias juvenis são compartilhadas com as das gerações de pessoas não jovens, portanto, edificadas por experiências de vida relativamente comuns aos moradores da e na periferia. Tal contextualização abrange aspectos como a localização e as dinâmicas sociais e políticas envolvidas no processo de urbanização do sítio.

Situado numa área de fronteira político-administrativa entre o município de Contagem e o de Belo Horizonte, o Estrela D'alva teve sua ocupação decorrente da abertura de loteamentos em áreas de fazendas e de chácaras de veraneio no período entre final dos anos de 1970 e década de 1980 (Registros de Campo, 2013). A ocupação, decorrente do parcelamento do solo feito informalmente e alheio a qualquer tipo de planejamento ou regulação urbana, gerou problemas de natureza fundiária, impossibilitou a regularização do registro ou de escritura dos imóveis e, além destes, problemas ambientais graves, tais como acúmulo de lixo, esgotamento a céu aberto e erosão aguda do solo. Tal erosão, o "buracão", atingiu a dimensão de uma grande cratera, que ao longo dos anos de 1990 e início dos anos 2000 representou um dos principais problemas locais. Segundo os moradores mais antigos "[...] cabia um prédio de nove andares no buracão" (Registros de Campo, 2013). A memória do "buracão" remete a tragédias coletivas representadas por episódios como soterramento de casas e a morte de pessoas, como expressa o relato de uma moradora pioneira no lugar.

E dentro do buracão não ficou ninguém, e na beirada do buracão ficou, e alguns caíram lá embaixo com a casa e tudo, e teve gente que morreu, teve uma menina de cinco anos que a enxurrada carregou ela e nós fomos achá-la juntamente com o Corpo de Bombeiros lá na Lagoa da Pampulha. A Defesa Civil era quem ajudava, vinha chuva e a gente ligava para a Defesa Civil e a gente passava a noite socorrendo as pessoas. (Entrevista com Maria, moradora que reside no bairro desde o início da ocupação - Registros de Campo, 2013).

O bairro Estrela D'alva foi ocupado por pessoas de origens diversas, principalmente migrantes vindos de municípios e regiões de Minas Gerais, como Miro, que nasceu no Vale do Jequitinhonha, uma das regiões com maior concentração de pessoas em situação de pobreza no estado. No início da ocupação, o bairro não contava com infraestrutura nem serviços públicos e a igreja católica era praticamente a única instituição coletiva existente no local. A partir da convivência religiosa os moradores se encontravam, trocavam informações, favores e discutiam os problemas coletivos do lugar. A igreja representava um importante espaço de interação social e de agenciamento da ação política na periferia desde os anos de 1980. Na época da minha pesquisa de campo, a vida religiosa mantinha uma função semelhante, além de representar uma das principais agências de regulação moral da vida social no Estrela D'alva.

Quanto ao processo de urbanização do bairro, pode-se dizer que foi lento e gradual, executado por "etapas" (período eleitoral), esteve relacionado às dinâmicas de troca de votos em troca de "favores" (Registros de Campo, 2013). A urbanização não se consolidou como direito e sim como moeda política, somente em 2010 a cobertura de serviços básicos como rede de esgoto, acesso à rede de distribuição de água e à rede elétrica atingiu todo o bairro, cobria $96 \%$ do total de 5765 dos domicílios situados no lugar (IBGE, 2014). Ao longo das três primeiras décadas de ocupação do sítio, a falta de infraestrutura e serviços urbanos básicos caracterizavam os principais problemas do bairro. Ao final da primeira década do século XXI, os problemas eram outros, como a violência e a expansão de atividades criminosas locais, do narcotráfico, principalmente.

Em 2008, Contagem era o $13 .{ }^{\circ}$ município com maior Índice de Homicídios de Adolescentes - IHA ${ }^{7}$ no ranking nacional das municipalidades, com mais de 200 mil habitantes, com 4,55 de IHA. A concentração dos problemas de violência e mortes fez com que o sítio fosse selecionado pelo governo municipal para receber, em 2010, o "Programa Conjunto, Segurança com Cidadania", gerido pela Organização das Nações Unidas do Brasil, cujo principal objetivo era a redução dos homicídios de crianças, de adolescentes e de jovens. Este Programa foi, em 2012, a porta de entrada no referido campo de pesquisa, onde por mais de 2 anos, por meio de etnografia, acompanhei jovens do bairro em esferas de interação relacionadas ao exercício de práticas culturais associadas ao hip-hop e à religião.

\section{Caminhos e dilemas rumo à vida adulta}

Os percursos para a vida adulta na contemporaneidade têm sido representados por experiências de vida que culturalmente servem de referência simbólica para demarcá-los socialmente, tais como a iniciação sexual, a saída de casa, o primeiro trabalho remunerado, o casamento, o nascimento do primeiro filho (Pais, 2009). Embora este campo de investigação seja recente no Brasil e, além disso, os contextos sociais considerados pelo referido autor sejam bastante distintos dos nossos, pois utiliza como referência os percursos de jovens portugueses e de outros países europeus, trata-se de uma referência bastante útil para a análise das trajetórias juvenis das sociedades contemporâneas em geral. O "deixar de ser criança" e o "tornar-se adulto" implicam muito mais que as mudanças fisiológicas corpóreas, 
envolvem um conjunto de representações e comportamentos sociais que traduzem tal condição. Ou seja, as experiências sociais que demarcam a transição da juventude para a vida adulta variam entre as sociedades e incidem sobre determinadas faixas de idade. Nas trajetórias dos jovens entrevistados, alguns eventos que demarcam a transição rumo à vida adulta aconteceram ainda na infância, como é para outros jovens da periferia, como expressou a fala de Faro:

Aqui, um menino vira homem mais cedo, a menina vira mulher muito mais cedo. Tem que aprender a correr por si mesmo, entendeu? Aprender a se virar no mundo mesmo, porque a situação infelizmente, para nós, é que as portas são fechadas muito mais vezes do que são abertas, entendeu? [...] A pessoa que não mora na periferia, eu não digo todos é claro, não todos, em geral tem uma vida financeira melhor, mora às vezes num apartamento ou numa casa legal, num bairro legal, tem um emprego bom, tem condição de manter o menino na escola sem ele ter que trabalhar, entendeu, [...] infelizmente, ou o menor de idade não consegue o trabalho ou o trabalho é muito pesado ou ele ganha pouco demais e a criminalidade aqui é a forma mais fácil se conseguir uma grana, mais fácil de conseguir um dinheiro bom, entendeu? (Faro, 2013: Entrevista 1.)

Se o impasse em relação ao futuro compõe um dos traços mais marcantes da condição juvenil contemporânea (Pais, 2009), para os jovens da periferia metropolitana de Belo Horizonte tal incerteza apresentava uma intensidade profunda. Tal sentimento, de incerteza, não se configurava pela questão "o que vou ser quando crescer?", mas sim por se tratar de um contexto no qual a transição para a vida adulta constituía-se a partir de um cenário em constante estado de crise, como interpretado em Feltran (2010: 45), a partir de etnografia feita na periferia paulistana: "[...] os modos de vida da nova geração já são, majoritariamente, conformados pela permanência destas «crises», e sua inescapabilidade." O autor destaca como problemática a inserção social vivida pelos jovens que desfrutam de um estatuto social semelhante ao de um "imigrante clandestino" (Feltran, 2010: 334). Se os filhos da periferia da metrópole paulista são confrontados com tal "inescapabilidade", na RMBH as trajetórias dos jovens da periferia seguiam rumos semelhantes, como expõe o trecho seguinte da fala de Miro:

Então, se eu estou neste mundão aqui, eu tenho que escolher: ou eu vou para o caminho certo ou eu vou para o errado. Qual que é o caminho certo? É trampar [trabalhar], fraga, ter um trampo honesto e ser um cidadão honesto. O caminho errado é traficar, vender droga, entrar pro crime, é roubar fraga. Tipo, você tem esses dois caminhos, cara, e aí, qual é o lado que eu vou seguir? Então, você fica na intermediária, você fica no meio, você não sabe se vai para o caminho certo ou para o errado. [...] E aí, você entra naquela, pois quando você amplia mesmo os seus conhecimentos é aquilo, porra, eu não quero ser do caminho errado, mas também não quero ser do caminho do bem. Porque o caminho errado é só o errado e o caminho do bem é só o caminho do bem, e a galera do bem às vezes são legais demais, são alienadas, entendeu, eles não querem se informar e nem querem informar as pessoas, mas e agora? [.. ] então eu vou ser alternativo, eu vou fazer as minhas paradas de bem, mas sabendo que está errado eu vou lutar contra, entendeu, então eu estou nesse meio, inserido nessa intermediária, é esse o peso que a rua te traz, essa responsabilidade. E se você está entrando no errado, segura sua onda então, mano, você vai ter que segurar sua onda no errado porque se você não segurar sua onda você cai. E aí você próprio vai se descobrindo, o que você é, qual é o seu papel na sociedade através da rua. (Miro, 2013: Entrevista 1.)

A compreensão de Miro sobre seu estar no mundo mostra que ao tornar-se adulto, fase na qual "amplia mesmo os seus conhecimentos", o jovem foi confrontado com um leque restrito de possibilidades de vida, e por isso questionava-se sobre quais caminhos seguir. O jovem via com desconfiança os caminhos predeterminados pela sociedade aos jovens da periferia representados no relato pelas categorias antagônicas e aparentemente excludentes denominadas por Miro por "caminho do bem" e "caminho do mal". As trajetórias dos dois jovens em foco denotam que os percursos juvenis e a transição para a vida adulta na periferia eram compostos por "caminhos" dos quais os jovens buscavam fugir por meio de "vias intermediárias". No Estrela D'alva este caminho alternativo não tinha como referência direta instituições tradicionais como família, escola ou igreja, era elaborada por fora destas: "[...] a rua te ensina, $[\ldots]$ você próprio vai se descobrindo, o que você é, qual é o seu papel na sociedade através da rua." (Miro, 2013: Entrevista 1.) As experiências sociais na "rua" expressam a relevância do espaço público na periferia como agência de integração social, ao mesmo tempo, o conteúdo das práticas sociais na "rua" era regado de influência das instituições sociais tradicionais, principalmente a igreja.

Na seção seguinte o texto prossegue evidenciando como nas trajetórias dos dois jovens a igreja 
foi uma agência cultural e política relevante na organização de seus percursos sociais e estruturação da vida social e comunitária na periferia (Registros de campo, 2013).

\section{Cultura juvenil na periferia: a busca por visibilidade pública e a vida comunitária}

Nas trajetórias de Faro e Miro a vida comunitária foi como um eixo por meio do qual suas ações eram orientadas. No convívio religioso, por exemplo, estes jovens praticaram-no atrelado ao enfrentamento dos problemas comunitários que, para sua geração, caracterizou-se pela expansão da criminalidade local e das dinâmicas de violência atreladas a ela. Situados nas margens da sociedade metropolitana, os jovens dispunham dos capitais produzidos pelo convívio religioso, como foi feito pelos moradores mais velhos quando o problema era a ausência de urbanização. Foi por meio da Primeira Igreja Batista do Estrela D'alva, a PIBED, cujo foco da ação religiosa era representado pela missão de "cuidar de pessoas", de "resgatar vidas", que Miro e Faro tiveram suas experiências religiosas na adolescência. Neste processo os jovens tinham um papel de destaque, na medida em que representavam os principais protagonistas e vítimas dos problemas contemporâneos do bairro. Isso fazia com que a participação juvenil na religião assumisse um tom de militância contra o envolvimento juvenil na criminalidade, como foi para Miro e Faro.

A participação juvenil na igreja era diferenciada da dos demais fiéis, na PIBED havia aos domingos o "Culto de adolescentes", um espaço exclusivo para os jovens, embora os cultos fossem ministrados por adultos. Durante o primeiro semestre de 2014 frequentei aos domingos os cultos exclusivos para os adolescentes e jovens, em geral na faixa de 13 a 17 anos de idade. Com objetivo de compreender as trajetórias de Miro e Faro apresenta-se a seguir uma breve descrição destes cultos que ocorriam semanalmente entre $18: 30 \mathrm{~h}$ e as $21: 00 \mathrm{~h}$ em um salão próprio e autônomo em relação ao restante da igreja PIBED. O espaço tinha o teto forrado com telhado de amianto e era equipado com cerca de 60 cadeiras, ao centro um pequeno palanque onde ficavam os equipamentos de som e os instrumentos musicais. Neste culto, além da pregação e das músicas ao vivo, era comum haver apresentações de teatro e dança pelos jovens. Os adolescentes fiéis eram convidados também a participarem de atividades como gincanas e outros eventos desenvolvidos pela igreja, como congressos e seminários nos quais participavam jovens residentes noutros sítios da RMBH. A partir destes eventos os jovens tinham a oportunidade de conhecer outros sítios e pessoas, de realizarem algum tipo de trânsito social que fora da religião dificilmente fariam (Registros de Campo, 2014).

Dentre as inúmeras particularidades que envolviam a participação juvenil na religião cristã, a segregação sexual e a proibição do namoro aos menores de dezoito anos foram mencionadas por Miro e Faro como fatores constrangedores para jovens que se formam "homem mais cedo" ou "mulher muito mais cedo" (Faro, 2013: Entrevista 1). Aos 16 anos este jovem decidiu namorar: "você quer fazer isso, então faz, mas você não vai poder dançar mais, [...] então, quando eu cismei de namorar, você quer saber? eu já sabia disso". Não se tratava de uma decisão simples para jovens que desde crianças possuíam a religiosidade enquanto principal referência herdada das relações familiares, "eu fiz minha vida ali, dentro da igreja" (Faro, 2014: Entrevista 2). Para Miro, por exemplo, o beijo na boca foi aos 10 anos e aos 12 começou a "namorar sério dentro de casa". Esse descompasso entre percursos de vida e normas institucionais gerou, a este jovem, impedimentos para o exercício das atividades que desenvolvia na igreja.

Ao mesmo tempo a religiosidade representava também uma bandeira de oposição à criminalidade a partir da qual os jovens combatiam os efeitos perversos das dinâmicas criminosas sobre a vida de outros jovens do bairro.

Teve um vizinho dele que tinha tomado uma bala no ombro, pegou no ombro, mas passou pelo osso e atravessou o braço dele inteiro e saiu na mão do vizinho dele que foi parar no hospital e a gente foi atrás. Já teve também casos de ter que intermediar algumas coisas, assim tipo briga dos caras, fraga, quando sabia que podia gerar algum conflito a gente ia e sentava com um e depois sentava com o outro e tentava sentar com todos juntos pra poder resolver. (Faro, 2014: Entrevista 2.)

Desde a época da ocupação do bairro a prática religiosa foi orientada também pelos moradores da periferia como um recurso político privilegiado de ação no espaço público relacionada à reinvindicação por infraestrutura e serviços urbanos. Nas trajetórias dos jovens Miro e Faro o conteúdo político da prática religiosa tinha outro foco, prevenir ou remediar a violência. Como indicou o trecho supracitado por Faro, a partir da religião o jovem buscava mediar conflitos violentos situados fora do âmbito da igreja em espaços como ruas, becos, esquinas e até hospitais quando envolvessem integrantes da célula ou mesmo amigos de infância. Os jovens buscavam evitar o pior, a morte violenta de algum amigo ou qualquer outra pessoa do bairro através do capital social produzido na religião. Nesta mesma linha de ação seguia a prática religiosa nas favelas do Rio de Janeiro, onde 
as igrejas desempenhavam um importante papel de regulação dos efeitos da violência sobre a vida comunitária (Birman e Machado, 2012). Segundo os autores, o discurso religioso possuía como principal bandeira a contraposição ao envolvimento com o crime, tinha a missão de resgatar da morte o povo de Deus (Birman e Machado, 2012: 64).

Retomando a trajetória de Miro, quando o jovem estava com 17 anos de idade seus percursos na religião assumiram rumos contrários, como será descrito na sequência, por um descompasso entre a ordem social imposta pela instituição religiosa (conservadora) e seus trajetos de vida (alternativos). A proibição do namoro aos menores de 18 anos era incompatível para um jovem que iniciou sua vida afetiva/sexual ainda aos 12 anos de idade. Tal regra soava como caduca e injusta na fala de Miro, principalmente por se tratar de uma época na qual o jovem dedicava-se com afinco à vida religiosa. Nessa época, durante o turno escolar o jovem pregava o evangelho para seus colegas, realizava testemunhos durante o recreio e lia a Bíblia em casa ou na de amigos. No final de semana Miro dedicava-se a atividades como ensaios e apresentações do seu Ministério de Dança, à realização da Célula da qual era líder, além do culto principal. Seus percursos na religião mostravam ao jovem que na igreja "acertos" e "erros" tinham pesos diferentes, "fazer a parada certa" gerava menos reconhecimento social se comparado ao cometimento de um erro. "Quando você erra, mano, os caras já vêm para cima de você, irmão" (Miro, 2013: Entrevista 1).

O "errar" proporcionava castigos públicos dentro da comunidade religiosa, tais como o impedimento do jovem de exercer suas atividades na célula, no grupo de dança e/ou de participar de eventos como seminários e encontros promovidos pela instituição. A partir da etnografia coloca-se como reflexão o fato de que este desequilíbrio entre "acertos" e "erros" não seja algo exclusivo da ordem e ideologia religiosa judaico-cristã mas antes um senso de justiça social focado na punição como mecanismo de purificação do corpo social. O foco na punição destituiu o jovem de sua razão e produziu em Miro uma visão de mundo que reconhece "que tudo está errado", o que fragilizou a legitimidade da religião enquanto projeto de vida, como expõe sua fala:

E com os dezessete fui ficando revoltado com algumas coisas que na minha visão eram erradas dentro da igreja, e ainda são, e eu fui e falei, já que está tudo errado, eu vou fazer da maneira que eu acho que é correto, saca. Então eu comecei a fazer umas paradas e fui sendo vetado de altas coisas dentro da igreja e que deu em resultado a minha saída. Nisso, logo que eu saí da igreja eu me envolvi com o tráfico. (Miro, 2013: Entrevista 1.)
A participação de Miro no narcotráfico teve duração de quase dois anos e seu término não foi uma consequência do retorno do jovem à igreja, resultou da participação deste nas ações do Projeto Social Mídia Tática desenvolvido no bairro por interveniência do Programa da ONU. O que atraiu Miro ao projeto foram os cursos gratuitos de rimas, grafite, e história da cultura hip-hop. O Projeto utilizava também como estratégia de prevenção da violência a ocupação positiva de espaços públicos ociosos ou abandonados no bairro, como foi o caso da Casa Amarela. Embora o hip-hop tivesse sido praticado por Miro dentro da igreja durante sua adolescência, foi a partir da intervenção do Projeto Mídia Tática que novas possibilidades de expressão desta cultura emergiram para o jovem. E o hip-hop passou a ser praticado como um instrumento de intervenção pública, de contraposição ao narcotráfico e de visibilidade social, compondo um novo repertório de "vias alternativas" de Miro.

Outro ponto, e que se configurou como uma inflexão na trajetória de Miro relacionado a sua saída do tráfico de drogas e sua integração ao Projeto Mídia Tática, foi o interesse despertado no jovem pela leitura e pela escrita, em voltar a estudar, fazer cursos e tirar o diploma do ensino básico. 0 jovem encontrava-se em busca de novos rumos de vida:

Eu comecei a dar oficinas de break, comecei a fazer oficinas de rima, me formei, e aí comecei a fazer curso de literatura e aí eu me formei como poeta. Hoje eu sou escritor e poeta. E depois eu comecei a fazer curso de designer fotográfico e a mexer com edições e tal, [...] eu me formei ano passado no $3 .^{\circ}$ ano [último ano do ensino médio] na Cesec [Centro de Educação Continuada] e nesse ano entrei pra faculdade. (Miro, 2013: Entrevista 1.)

Durante a pesquisa etnográfica observei no bairro um movimento de expansão ou de aumento da visibilidade da cultura hip-hop que se expressava como uma nova manifestação da cultura juvenil naquela periferia. Nessa época, no primeiro semestre de 2012, Miro, junto aos seus pares, realizava eventos semanais relacionados à cultura hip-hop, como danças, duelos de rimas, apresentação de filmes e documentários ao ar livre em espaços públicos do bairro como ruas e praças. Na rua central do centro comercial do bairro, como noutras adjacentes, era comum avistar grafites em muros e fachadas de lojas, bem como jovens transeuntes vestidos com bonés de aba reta, camisetas de grupos de rap, como "Racionais MC's", "Facção Central", toucas, calças largas e correntes grossas dependuradas sobre os bolsos e/ou pescoço. A estética do hip-hop marcava a presença juvenil no espaço público e na web por 
meio do compartilhamento de imagens postadas na plataforma virtual Facebook.

Através da apropriação dos espaços públicos os jovens produziam "políticas de existência" (Ferreira, 2008) a partir de performances corporais e visuais impressas na paisagem urbana local. Tais ações fortaleciam os vínculos comunitários dos jovens e ao mesmo tempo eram úteis para testarem suas competências individuais valoradas perante seus pares. Nesta perspectiva, corrobora-se com Campos (2010: 116) sobre "o peso crescente do campo visual na determinação e negociação de identidades e práticas culturais" (Campos, 2010: 116), e, assim, reconhece-se a questão da visualidade como algo cada vez mais relevante para a compreensão das práticas juvenis contemporâneas. zindo também uma expressão do desejo de consolidação de práticas legítimas juvenis no espaço público da periferia, fora de instituições como igreja, escola e tráfico de drogas. Todavia, esse desejo não se consolidava plenamente devido ao fato de fora destas últimas esferas, estruturais em nossa sociedade, a ação juvenil se encontrar fragilizada, pois os jovens não dispunham de fontes de recursos materiais e apoio político de tais instituições. Apesar disso, por meio dessas ações, os jovens imprimiam uma nova gramática de ação coletiva na periferia, elaborando um pensamento crítico em relação à religião e à política desempenhada pelos governos ${ }^{8}$, que também servia como bandeira contrária ao envolvimento juvenil no crime.

Figura $1 \triangleright$ Festival de dança de rua e Mostra de filme ao ar livre: E. D'alva-2013

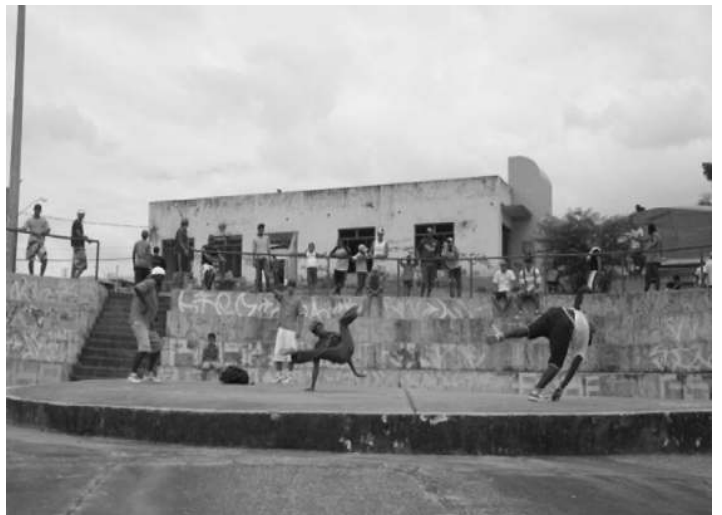

Fonte: Registros de Campo, 2013

A propagação de imagens e mensagens na periferia não servia apenas como cenário para os eventos relacionados à cultura hip-hop, tradu-

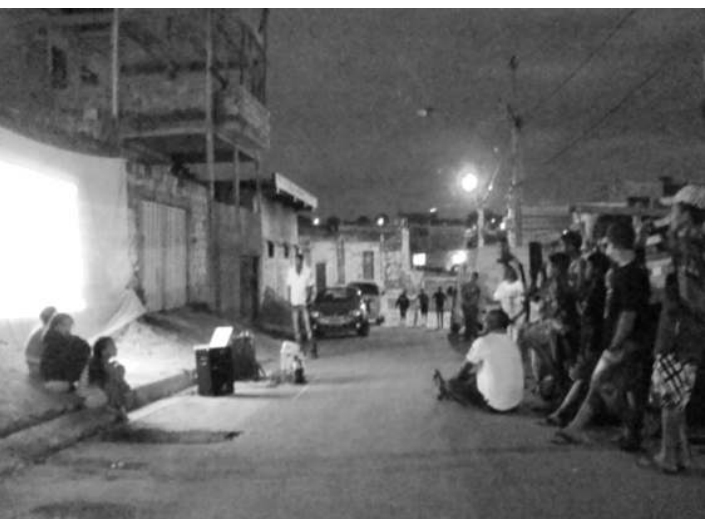

Diferentemente da religião, do tráfico de drogas e do jogo político eleitoreiro que possuem fontes de recursos em níveis razoáveis, o hip-hop

Figura $2 D$ Jovens e Grafites: E. D'alva-2013
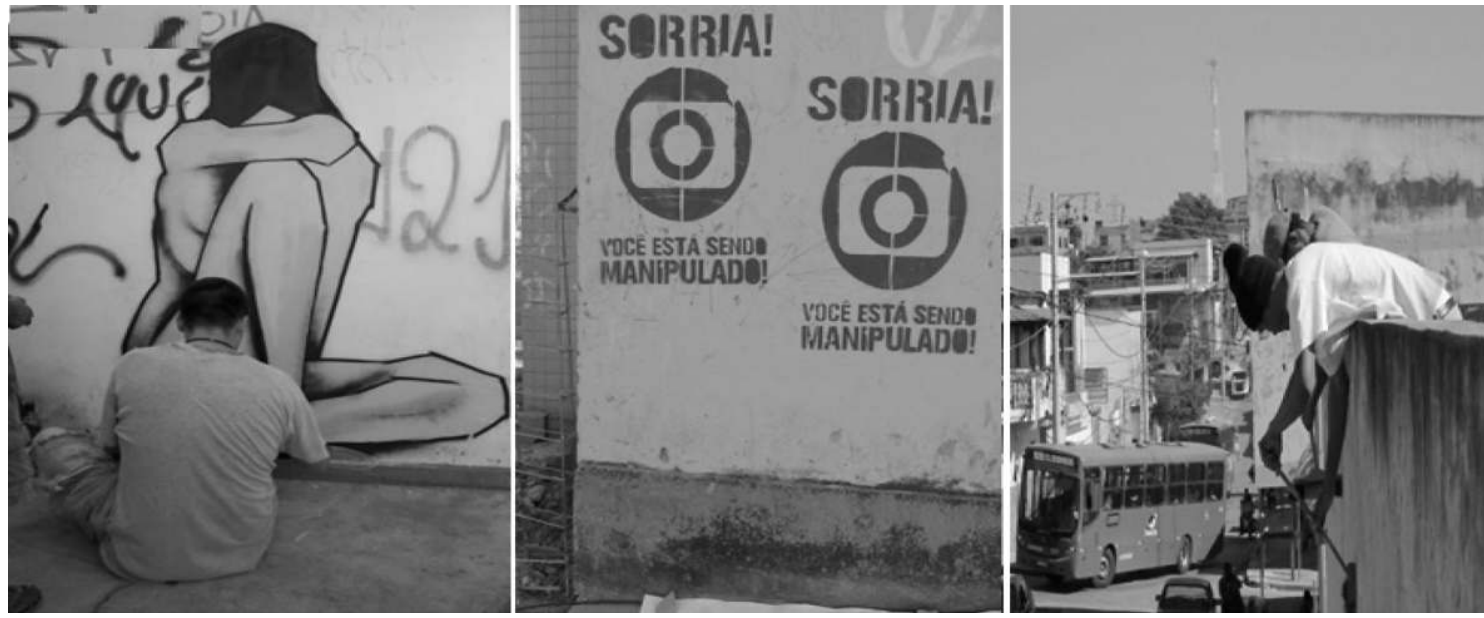

Fonte: Registros de Campo, 2013

\section{E Sociológico}

N. 26 (Iㅡére, 2015)

pp. 43-52 
era patrocinado basicamente pelos parcos recursos dos jovens. Inicialmente, tais ações recebiam apoio governamental, como equipamentos de som cedidos da Secretaria Municipal de Cultura e tintas para grafite; contudo, à medida que as ações do Programa da ONU se iam encerrando, no bairro diminuía a presença e a intensidade do apoio do governo municipal às atividades desenvolvidas pelos jovens. De um modo geral eram os jovens que arcavam com os custos de transporte do material e de acessórios, como máscaras de proteção facial, ocular, querosene e flanela, necessários para o grafite. O hip-hop exigia investimentos e ao mesmo tempo não gerava rendimentos. No bairro o crime representava para os jovens como Faro, por exemplo: "a forma mais fácil de conseguir uma grana, mais fácil de conseguir um dinheiro bom" (Faro, 2013: Entrevista 1).

Resistir à igreja por meio do hip-hop no espaço público não era uma tarefa simples e motivadora, muitas das vezes havia nos duelos somente o público cativo, fiel. Por outro lado, as igrejas contavam com uma infraestrutura de palco, equipamentos de som e maior número de pessoas. Na rua, os jovens estavam sós. Por mais que o hip-hop estivesse presente no campo visual e sonoro da periferia, não era uma atividade consolidada na periferia, a quantidade de jovens participantes deste movimento cultural era parca, especialmente se comparada à participação juvenil nas igrejas. Em relação ao tráfico de drogas não era diferente, a atividade, embora ilícita, possuía fontes de recursos próprios, pontos de venda fixados no território. Tendo em vista estas questões pode-se dizer que o hip-hop se configurava para os jovens como uma forma de resistência exercida à proteção alienante da igreja e ao arriscado envolvimento com a criminalidade.

\section{Considerações finais}

Este artigo apresentou em síntese alguns dos principais resultados da investigação de trajetórias juvenis na periferia metropolitana de Belo Horizonte. No contexto contemporâneo brasileiro, a "periferia" representa o locus do conflito violento no território urbano (Vieira da Cunha e Feltran: 2013), onde os homicídios atingem as taxas mais elevadas nas últimas décadas (Andrade et al., 2013). As experiências juvenis no Estrela D'alva eram então atravessadas pelas dinâmicas decorrentes das atividades criminosas e violentas instaladas no bairro. A vida religiosa, por exemplo, era praticada pelos jovens como meio para resolução de conflitos violentos envolvendo amigos e conhecidos, e era orientada para a prevenção da violência na periferia. De modo semelhante às gerações anteriores, as trajetórias de vida de Miro e Faro foram orientadas pelas dinâmicas da vida local segregada na periferia metropolitana. 0 acesso ao trabalho, o namoro e as relações escolares estruturavam-se em torno das dinâmicas da vida local e era na igreja ou com algum conhecido que os jovens conseguiam trabalho, realizavam atividades de lazer, ou davam curso a outras práticas culturais exercidas na periferia.

Concomitantemente, os percursos juvenis no Estrela D'alva eram conformados por experiências de transição para a vida adulta (Pais: 1991) que se estruturavam ainda durante a infância. Nas trajetórias dos jovens entrevistados, a inserção no mundo do trabalho, as experiências sexuais e o abandono escolar foram precoces, iniciando-os bem cedo na passagem para a idade adulta - recorde-se que Miro, aos 12 anos, fazia biscates e "namorava sério dentro de casa". Tal precocidade contribuía para segregar na periferia os jovens adultos da periferia, gerando tensões sobre a construção dos seus projetos de vida que se traduziam e uma necessidade de encontrar saídas, como expôs a ideia do "caminho alternativo", que afinal de contas não levava para fora da periferia. O "caminho alternativo" era mais incerto se comparado à previsibilidade dos caminhos do "bem" e do "mal" e tinha como referência fundamental a "rua", onde todos estes caminhos se cruzavam. Na periferia Faro e Miro encontraram formas de alargarem seus laços sociais, contudo mantinham poucas relações sociais em contextos mais amplos da metrópole.

Por fim, longe de querer aqui esgotar as possibilidades e limites de análise que as trajetórias permitem, reconhece-se que os percursos de vida de Faro e Miro expõem limites impostos em geral à inserção social de sujeitos que como eles partilham socialmente de um status semelhante ao do imigrante clandestino (Feltran, 2010). E que, embora as experiências juvenis na periferia não se resumam obviamente aos caminhos representados pela narrativa construída em torno destes jovens, suas trajetórias constituem referências relevantes para a compreensão da problemática da inserção social juvenil, em geral, no contexto metropolitano contemporâneo.

\section{Notas}

1 Texto excerto de trabalho Trajetória juvenil e vida social na periferia metropolitana de Belo Horizonte apresentado no " $1 .{ }^{\circ}$ Congresso da Associação Internacional de Ciências Sociais e Humanas em Língua Portuguesa 2015", Grupo de Trabalho 86B, sediado na Universidade Nova de Lisboa, Lisboa, 2015.

2 A noção de periferia adotada não tem um caráter eminentemente geográfico, mas é adotada como espaço limiar ou de fronteira social, como locus do conflito no contexto metropolitano contemporâneo como defendido em Vieira da Cunha e Feltran (2013), onde a violência expressou-se de forma mais intensa e visível nas duas últimas décadas no território brasileiro (Andrade et al., 2103). 
3 Todos os nomes próprios utilizados nesse artigo são fictícios.

4 O movimento hip-hop no Brasil existe há cerca de trinta anos de forma dispersa e pouco registrada. De um modo geral se constitui de quatro elementos: o break (a dança de passos robóticos realizada em equipe ou não), o grafite (a pintura feita com spray e aplicada aos concretos da cidade), o DJ (o disc-jóquei) e o MC (o que declama poemas e atua como mestre de cerimônias). Sendo que destes dois últimos elementos em junção resulta o rap - abreviação de rythm and poetry, ritmo e poesia, em inglês (Zeni, 2004).

5 Segundo o IBGE (2015), por aglomerado subnormal pode se considerar um conjunto constituído por 51 ou mais unidades habitacionais caracterizadas por ausência de título de propriedade e pelo menos uma das características seguintes: irregularidade das vias de circulação e do tamanho e forma dos lotes e/ou carência de serviços públicos essenciais (como coleta de lixo, rede de esgoto, rede de água, energia elétrica e iluminação pública).

6 Localizada ao noroeste do município de Contagem, o segundo mais populoso no universo de 34 municípios da RMBH com 603442 habitantes, e terceiro em relação ao total de 853 municipalidades do Estado de Minas Gerais (Censo Demográfico de 2010).

7 O IHA, Índice de Homicídios na Adolescência, estima o risco de mortalidade por homicídio de adolescentes que residem em um determinado território (Secretaria Especial dos Direitos Humanos da Presidência da República - SPDCA/SEDH, UNICEF, Observatório de Favelas e Laboratório de Análise da Violência LAV/UERJ).

8 Havia no hip-hop jovens envolvidos tanto no crime como na religião, como de fora de ambos, combinação que expõe os trânsitos entre "caminhos" que buscam mediação por meio de interações ocorridas na "rua".

\section{Referências bibliográficas}

ANDRADE, L. T. et al. (orgs.) (2013), Homicídios nas regiões metropolitanas, Rio de Janeiro, Letra Capital.

BIRMAN, P. e C. Machado (2012), "A violência dos justos: evangélicos, mídia e periferias da metrópole", Revista Brasileira de Ciências Sociais, Out., vol. 27, n. ${ }^{\circ} 80$, pp. 55-69.

BOURDIEU, P. (1987), A economia das trocas simbólicas, São Paulo, Perspectiva.

BOURDIEU, P. (2000), Esboço de Uma Teoria da Prática: precedido de três estudos da etnologia cabila, Oeiras, Celta Editora.
CAMPOS, R. (2010), "Juventude e visualidade no mundo contemporâneo: Uma reflexão em torno da imagem nas culturas juvenis", Sociologia, Problemas e Práticas, Oeiras, vol., n.0 63, pp. 113-137.

CORDEIRO, G. Í. e F. Vidal (2008), "A rua: espaço, tempo, sociabilidade" in Etnográfica, novembro de 2009, 13 (2), pp. 483-493.

FELTRAN, G. S. (2010), Fronteiras de tensão: política e violência nas periferias de São Paulo, 1.a ed., São Paulo, Editora Unesp/CEM.

FERREIRA, V. S. (2008), Marcas que Demarcam. Tatuagem, Body Piercing e Culturas Juvenis, Lisboa, Imprensa de Ciências Sociais.

IBGE (2014), Instituto Brasileiro de Geografia e Estatística, Censo demográfico de 2010, Brasil, Rio de Janeiro.

KOWARICK, L. (1983), A espoliação urbana, São Paulo, Paz e Terra.

MACHADO DA SILVA, L. A. (2008), Vida sob cerco: violência e rotinas nas favelas do Rio de Janeiro, Rio de Janeiro, Nova Fronteira, 2008.

MARINHO, M. A. C. (2012), Homicídios e metropolização no Brasil: um estudo a partir da região metropolitana de Belo Horizonte, Dissertação (Mestrado) Pontifícia Universidade Católica de Minas Gerais. Belo Horizonte, Programa de Pós-Graduação em Ciências Sociais.

PAIS, J. M. (1991), "Emprego juvenil e mudança social: velhas teses e novos modos de vida", Análise Social, vol XXVI, $1991\left(5 .{ }^{\circ}\right)$, 945-987.

PAIS, J. M. (2008), "O visual e o quotidiano: razões de um encontro", in J. M. Pais et al. (orgs.), O visual e o quotidiano, Lisboa, Imprensa de Ciências Sociais, pp. 19-20.

PAIS, J. M. (2009), "A Juventude como Fase de Vida: dos ritos de passagem aos ritos de impasse", Saúde e Sociedade, 18 (3), 371-381.

PLAMBEL (1986), A estrutura urbana da RMBH - V.1 - O processo de formação do espaço urbano 18971985. Belo Horizonte, Plambel.

VIEIRA DA CUNHA, N. e G. S. Feltran (2013), Sobre periferias, Novos conflitos no Brasil Contemporâneo, Rio de Janeiro, Lamparina \& Fapesp.

ZENI, B. (2004). O negro drama do rap: entre a lei do cão e a lei da selva, in $O$ negro no Brasil. Estudos avançados, São Paulo, USP, V18, n. ${ }^{\circ}$ 50, jan./ /abril, pp. 225-241.

* Bolseiro da Coordenação de Aperfeiçoamento de Pessoal de Nível Superior (Capes), fundação do Ministério da Educação (MEC) - CAPES/PDSE no: 99999.005065/2014-03.

Marco Marinho (coutomarinho@gmail.com). Pontifícia Universidade Católica de Minas Gerais, Faculdade de Ciências Humanas, Programa de Pós-Graduação em Ciências Sociais (PPGCS-PUC Minas) \& Universidade Nova de Lisboa, Centro Interdisciplinar de Ciências Sociais (CICS-NOVA). Programa de Pós-Graduação em Ciências Sociais (PPGCS-PUC Minas), Avenida Itaú, 505, $3^{\circ}$ andar, Bairro Dom Cabral, 30535-012 Belo Horizonte, Minas Gerais, Brasil. 